\title{
Microbial Monitoring of Common Opportunistic Pathogens by Comparing Multiple Real-Time PCR Platforms for Potential Space Applications
}

\author{
Cherie M. Oubre ${ }^{1}$ \\ Wyle, Houston, TX, 77058, USA \\ Michele N. Birmele ${ }^{2}$ \\ Sierra Lobo, Inc., Kennedy Space Center, FL, 32899, USA \\ Victoria A. Castro ${ }^{3}$ \\ Enterprise Advisory Services, Inc., Houston, TX, 77058, USA \\ Kasthuri J. Venkateswaran ${ }^{4}$ and Parag A. Vaishampayan ${ }^{5}$ \\ Jet Propulsion Laboratory, California Institute of Technology, Pasadena, CA, 91109, USA \\ Kathy U. Jones, ${ }^{6}$ Adesh Singhal, ${ }^{7}$ Angela S. Johnston, ${ }^{8}$ and Monserrate C. Roman ${ }^{9}$ \\ NASA Marshall Space Flight Center, Huntsville, AL, 35807, USA \\ Tamra A. Ozbolt ${ }^{10}$ \\ Emerald City Initiatives, Inc, Grant, AL, 35747, USA \\ Daniel X. Jett ${ }^{11}$ \\ Teledyne Brown Engineering, Inc., Huntsville, AL, 35807, USA \\ Michael S. Roberts ${ }^{12}$ \\ CSS - Dynamac, Kennedy Space Center, FL, 32953, USA \\ and \\ C. Mark Ott ${ }^{13}$ \\ NASA Johnson Space Center, Houston, Texas, 77058, USA
}

\footnotetext{
${ }^{1}$ Senior Scientist, Wyle, Houston, TX, 77058.

${ }^{2}$ Advanced Life Support Labs Lead, Engineering Services Contract, Team QNA, Mail code: ESC 24, Kennedy Space Center, FL 32899.

${ }^{3}$ Section Manager, Enterprise Advisory Services, Inc., Houston, TX 77058.

${ }^{4}$ Senior Research Scientist, Jet Propulsion Laboratory, California Institute of Technology, Pasadena, CA 91109.

${ }^{5}$ Staff Scientist, Jet Propulsion Laboratory, California Institute of Technology, Pasadena, CA 91109.

${ }^{6}$ Project Manager, Flight Programs and Partnerships Office, International Space Station Office, NASA Marshall Space Flight Center, Mailcode: FP10; Huntsville, AL 35812.

${ }^{7}$ Project Support, FP10, NASA Marshall Space Flight Center, Huntsville, AL 35812, Senior Member IEEE.

${ }^{8}$ Aerospace Technologist, Mission Support and Requirements Development, NASA Marshall Space Flight Center, Huntsville, AL 35807.

${ }^{9}$ Aerospace Technologist, Life Support Studies, NASA Marshall Space Flight Center, Huntsville, AL 35807.

${ }^{10}$ Engineer, Emerald City Initiatives, Inc., Grant, AL 35747.

${ }^{11}$ Senior Engineer/Project Manager, Teledyne Brown Engineering, 300 Sparkman Drive, Huntsville, AL 35805 MS60.

${ }^{12}$ Chief Scientist, Space Life Sciences, Center for the Advancement of Science in Space, Kennedy Space Center, FL 32953.

${ }^{13}$ Microbiologist, NASA Johnson Space Center, Houston, TX 77058.
} 
Because the International Space Station is a closed environment with rotations of astronauts and equipment that each introduce their own microbial flora, it is necessary to monitor the air, surfaces, and water for microbial contamination. Current microbial monitoring includes labor- and time-intensive methods to enumerate total bacterial and fungal cells, with limited characterization, during in-flight testing. Although this culturebased method is sufficient for monitoring the International Space Station, on future longduration missions more detailed characterization will need to be performed during flight, as sample return and ground characterization may not be available. At a workshop held in 2011 at NASA's Johnson Space Center to discuss alternative methodologies and technologies suitable for microbial monitoring for these long-term exploration missions, molecular-based methodologies such as polymerase chain reaction (PCR) were recommended. In response, a multi-center (Marshall Space Flight Center, Johnson Space Center, Jet Propulsion Laboratory, and Kennedy Space Center) collaborative research effort was initiated to explore novel commercial-off-the-shelf hardware options for space flight environmental monitoring. The goal was to evaluate quantitative or semi-quantitative PCR approaches for low-cost in-flight rapid identification of microorganisms that could affect crew safety. The initial phase of this project identified commercially available platforms that could be minimally modified to perform nominally in microgravity. This phase was followed by proof-of-concept testing of the highest qualifying candidates with a universally available challenge organism, Salmonella enterica. The analysis identified two technologies that were able to perform sample-to-answer testing with initial cell sample concentrations between 50 and 400 cells. In addition, the commercial systems were evaluated for initial flight safety and readiness.

$\begin{array}{ll}{ }^{\circ} \mathrm{C} & =\text { degrees Celsius } \\ \mathrm{CFU} & =\text { colony-forming unit(s) } \\ \mathrm{DNA} & =\text { deoxyribonucleic acid } \\ \text { ISS } & =\text { International Space Station } \\ \mathrm{JPL} & =\text { Jet Propulsion Laboratory } \\ \mathrm{JSC} & =\text { Johnson Space Center } \\ \mathrm{KSC} & =\text { Kennedy Space Center } \\ \text { LLOD } & =\text { lower limit of detection } \\ \text { MMS } & =\text { Microbial Monitoring System } \\ \text { PCR } & =\text { polymerase chain reaction } \\ \text { rpm } & =\text { revolutions/minute } \\ \text { TSA } & =\text { tryptic soy agar }\end{array}$

\section{Nomenclature}

\section{Introduction}

$\mathrm{S}^{\mathrm{s}}$ pace vehicles must maintain a closed environment with sustainable environmental control systems to recycle air and water. The environment is designed to support rotations of astronauts and equipment, which add to its microbial flora. These unique challenges make it necessary to monitor the air, surfaces, and water in the interior of a spacecraft for microbial contamination, to identify remediation needs and prevent adverse effects on crew health and space flight systems. ${ }^{1-3}$ Current environmental monitoring procedures require labor- and time-intensive methods to enumerate total bacterial and fungal cells during in-flight testing, but characterization capability is limited. Enumeration and total coliform testing are performed during flight, but samples are returned to the ground for characterization. Samples are typically taken from air, water, and surfaces of the International Space Station (ISS) at regular intervals (such as every 3 months), and if microbial cell counts exceed specific limits (e.g., 50 colonyforming units- $\mathrm{CFU}$ - per $\mathrm{ml}$ for total bacteria and $0 \mathrm{CFU}$ for coliform bacteria for pre- and in-flight water samples), then specific decontamination actions are taken. ${ }^{3}$

Although the current system has proven to be sufficient for the ISS and has protected the crews and vehicle from serious defect, multiple subsystems on the ISS have been affected by microbial growth. ${ }^{3}$ In 2011 , a workshop was 
held at NASA Johnson Space Center (JSC) to discuss alternative methodologies and technologies suitable for microbial monitoring on long-term missions. ${ }^{4}$ Subject matter experts from industry and academia made recommendations suggesting that implementation of molecular-based technologies such as real-time polymerase chain reaction (PCR) should be evaluated for supplementation and eventual replacement of the current culture-based technologies for long-duration missions. As a result of this recommendation a project was initiated to identify commercial technologies that could be used to perform time-critical microbial monitoring of ISS crew health and the water processing and dispensing system. The objective of the project was to perform a market survey of applicable, state-of-the-art technologies and develop proof-of-concept testing matrices to evaluate existing commercial technologies for use in an in-flight, near-real-time microbial monitoring system. The initial step in this process was to evaluate technologies for microbial monitoring of air, water, and surfaces to prevent or minimize impacts on ISS operations and crew health. To meet budget and schedule constraints, this effort was initially focused on technologies for monitoring potable water quality. The long-term goal of the project is to develop a microbial monitoring system that will

1. Enable rapid assessment of the microbial environment of the ISS, which will lead to expedited operational decisions.

2. Enable monitoring for additional microbes (beyond the current capability).

3. Reduce the required frequency of sampling.

4. Enable better and/or more targeted responses to cope with anomalies.

5. Allow crews to be more independent of the Earth for identification of microbes that affect ISS systems and crew health.

To be considered for the next generation of microbial monitoring hardware to be used on board the ISS, the candidates must use quantitative or semi-quantitative PCR technology. The chosen unit will need to function properly in a microgravity environment (using such technologies as microfluidics and thermal management), meet the appropriate ISS interface and safety requirements, and be autonomous after the sample is inserted into the cassette or sample envelope.

As mentioned previously, a market survey was performed to identify commercially available platforms (see Appendix). Three commercially available systems were evaluated during proof-of-concept testing. The proof-ofconcept testing was performed using these systems with a universally available challenge organism (Salmonella enterica). In addition, a preliminary qualitative flight assessment was included as part of the overall evaluation.

1. Cepheid's SmartCycler ${ }^{\circledR}$ is a real-time PCR instrument that has as many as 96 sites and can test 16 different protocols simultaneously. With an average time-to-results of 20-40 minutes, the SmartCycler System can deliver results in less than half the time of a 96-well plate instrument. This high-throughput instrument achives faster results with its high thermal conductivity ceramic heater plates, coupled with a high-efficiency fan. Some of the other key features of this system are easy-to-optimize PCR protocols, easy installation and system expansion, user-friendliness (plug and play), no routine maintenance, and ideal for field work because the I-CORE module is a solidstate optical system with no moving parts.

2. BioFire Diagnostics (formerly known as Idaho Technologies, Inc.) RAZOR ${ }^{\circledR} \mathrm{EX}$ is a field -portable real-time semi-quantitative PCR instrument designed for use by the military and first responders for the detection and identification of biological agents (i.e., microorganisms) in environmental samples. Raw samples are loaded into a reagent pouch system containing freeze-dried reagents. Up to 12 reactions per single sample or up to 12 different samples can be processed in a single pouch. BioFire Diagnostics manufactures preformatted reagent pouches (like the one for water testing shown in Fig. 1), or users can create custom-designed reagent pouches for

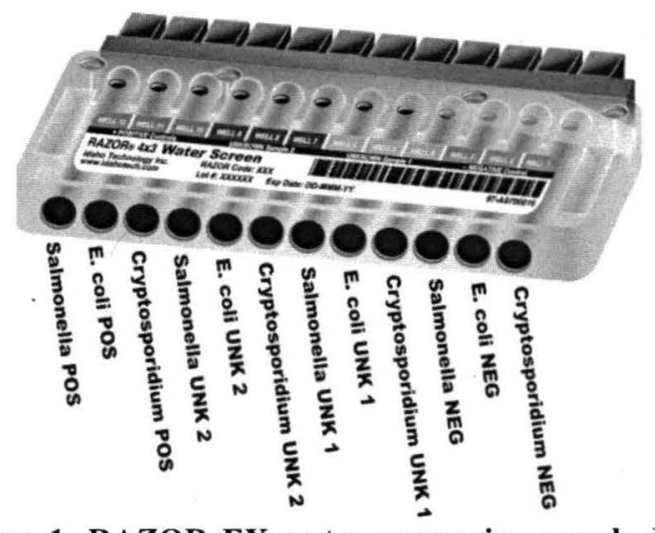

Figure 1. RAZOR EX water processing pouch. Each pouch contains 3 targets (Cryptosporidium, Salmonella, and Escherichia coli) that are relevant to water systems monitoring. For this evaluation, the food pouch that detects Campylobacter, Listeria monocytogenes, and Salmonella was also utilized. Image from BioFire Diagnostics website: http://www.biofiredx.com/ RAZOREX/index.html. 
use in different environments for the detection of other microorganisms of interest.

3. The iCubate 2.0 system developed by iCubate, Huntsville, $\mathrm{AL}$, is a multiplex semiquantitative PCR technology that allows a sample to answer processing in a self-contained cassette. The cassette is preloaded with all required $\mathrm{PCR}$ reagents, including positive and negative controls and up to 30 different primers, allowing evaluation of up to 30 microbial targets in each reaction/cassette. The company has the ability to custom produce cassettes with specified targets that could be designed for current and future space flight needs. A detailed video of the iCubate process is available on-line at http://icubate.com/index.php/ technology/video-overview/.

The iCubate system performs a multiplex PCR assay using amplicon-rescued multiplex PCR and polymerase preference index, an algorithm developed to help

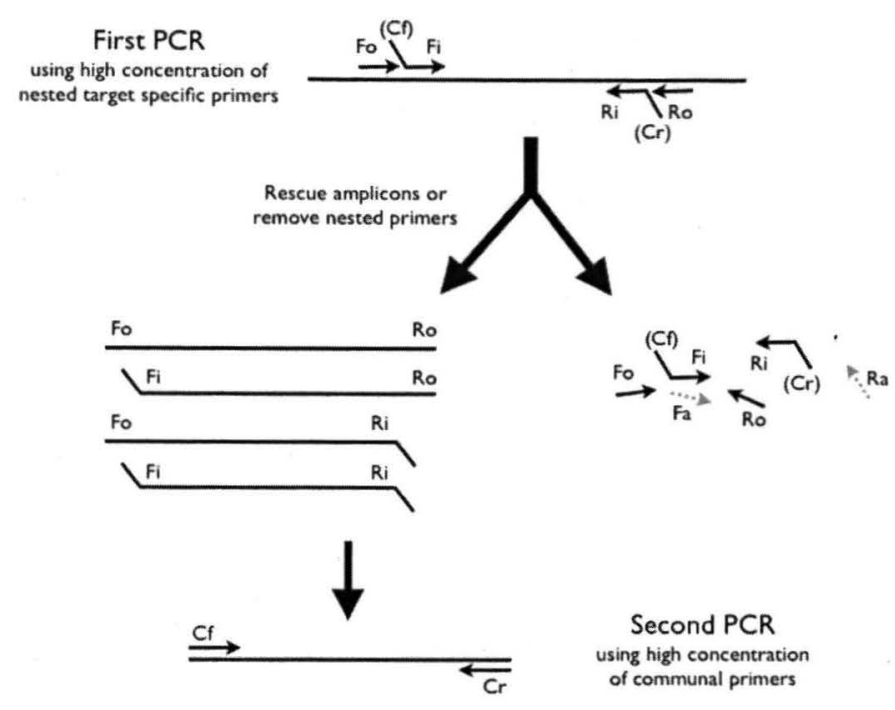

Figure 2. iCubate amplification technology. The technology includes the use of specific nested primers during round 1 of amplification, followed by communal primers in round 2 to improve sensitivity and decrease time required for amplification. Image from iCubate website: $w w w$.icubate.com reproduced with permission.

select the best performing PCR primers based on polymerase preference. A high concentration of targetspecific, nested primers is used in the initial PCR round. Then the amplicon is rescued and a second round of PCR is performed by adding fresh communal primers (recognizing the shared tag sequence already introduced during the first round of amplification) and enzymes (Fig. 2). The amplicons are then hybridized to an array on a glass slide and array detection is performed using the rotating reader.

The results of this market research and proof-of-concept testing were used to develop requirements for a competitive procurement of a commercial-off-the-shelf PCR unit. The selected PCR unit will be evaluated in much more detail to identify risks to the flight qualification of an integrated microbial monitoring system that would be used on board the ISS. The long-term goal of this work is to provide crews with a platform capable of in-flight automated detection of a wide variety of target compounds. This function will be critical for long-duration missions to the moon or beyond where reliance on Earth analysis may not be possible. Just as terrestrial medicine is moving toward individualized medicine using multiplex PCR methods for diagnosis, ${ }^{5}$ space flight medical care will need this technology as we move toward exploration-class missions with limited space and sample-return capabilities. This project is a starting point for the development of state-of-the art environmental monitoring technology that has the potential for future expansion to include medical applications.

\section{Procedures}

Proof-of-concept testing was performed using three PCR-based platforms. The platforms included Cepheid's SmartCycler (testing performed by scientists at the Jet Propulsion Laboratory [JPL]); iCubate's iCubate 2.0 (testing performed by JSC scientists); and BioFire Diagnostics' RAZOR EX (testing performed by Kennedy Space Center $[\mathrm{KSC}]$ scientists). The testing organism, conditions, methods, and analysis were consistent across platforms and are described in this section. Any platform-unique elements are described in detail.

\section{A. Test organisms}

The challenge organism was Salmonella enterica (ATCC 14028), because it was the single target that all platforms had a reagent assay kit commercially available to detect. The functional negative control organism was 
Pseudomonas aeruginosa (ATCC 700888), as it is a common organism that has been recovered from ISS water systems.

Microbial test organisms (S. enterica and P. aeruginosa) were cultured, diluted, and shipped from the KSC laboratory to other testing sites (JPL and iCubate facility). All test organisms were maintained on tryptic soy agar (TSA), were transferred weekly, and were no more than three passages removed from the original source. Overnight broth cultures were prepared in quadruplicate with a media negative control in $75 \mathrm{~mL}$ tryptic soy broth $(30 \mathrm{~g} / \mathrm{L})$ incubated in an environmental shaker at $37 \pm 2^{\circ} \mathrm{C}$ at $125 \pm 60 \mathrm{rpm}$ for 18-24 hours. The density of viable bacteria was checked by serial dilutions (1:10) and plating on TSA. Plates were incubated for $18-24$ hours at $37 \pm 2^{\circ} \mathrm{C}$ before enumeration.

Optical densities of broth cultures were taken on a spectrophotometer (Genesys 20 ThermoSpectronic, Madison, WI) at $590 \mathrm{~nm}$ to approximate the bacterial concentration of the inoculum during the incubation in order to identify the cellular suspension during mid-log phase in the growth cycle. Once the bacterial suspension reached the approximate desired optical density $\left(\lambda_{590 \mathrm{~nm}}=0.1\right.$ or $1 \times 10^{8}$ cells $\left./ \mathrm{mL}\right)$, the cells were triple rinsed to remove excess carbon by centrifuging at $5000 \mathrm{rpm}$ for 5 minutes and decanting the supernatant. The cells were then resuspended in $1 \mathrm{X}$ phosphate buffer saline (PBS).

Serial dilutions $(1: 10)$ of challenge organisms were prepared, ranging from $1 \times 10^{5}$ to $1 \times 10^{2} \mathrm{CFU} / \mathrm{mL}$ in molecular-grade sterile deionized water and/or ISS simulant water (provided by JSC). ISS simulant water is water collected on the ISS from the potable water supply, returned to the Earth and filtered through a 0.2 micron filter. The negative operational reagent control (no-template control) consisted of the same components used to make the suspensions minus the challenge organisms. The functional negative control was prepared as described above using the same concentration of $P$. aeruginosa bacterial cells.

After the minimum cellular concentration or lower limit of detection (LLOD) was determined for each platform for $S$. enterica, mixed-culture samples using both challenge organisms at the same concentration were prepared to determine if inhibition would occur. The cellular concentrations were varied by platform as indicated below:

1. SmartCycler - The SmartCycler platform LLOD for $S$. enterica was determined to be 94 cells/reaction. Hence, combinations of $S$. enterica and $P$. aeruginosa were tested at concentrations ranging from $1 \times 10^{3}$ $\mathrm{CFU} / \mathrm{mL}$ to $1 \times 10^{6} \mathrm{CFU} / \mathrm{mL}$.

2. RAZOR - The RAZOR EX platform LLOD for $S$. enterica was determined to be $5 \times 10^{2} \mathrm{CFU} / \mathrm{mL}$ ( 50 cells/reaction). Based on this level of detection, combinations of $S$. enterica and $P$. aeruginosa were tested at concentrations ranging from $1 \times 10^{3} \mathrm{CFU} / \mathrm{mL}$ to $1 \times 10^{6} \mathrm{CFU} / \mathrm{mL}$.

3. iCubate - The LLOD for S. enterica was determined during testing with the iCubate platform to be $1 \times 10^{4}$ (400 cells/reaction). As a result, combinations of $1 \times 10^{5} \mathrm{CFU} / \mathrm{mL}$ and $1 \times 10^{6} \mathrm{CFU} / \mathrm{mL}$ of $S$. enterica and $P$. aeruginosa were used for competitive tesing.

Salmonella enterica DNA samples were prepared at JPL at a concentration of $1 \times 10^{5} \mathrm{CFU} / \mathrm{mL}$ and used on each platform to determine detection variability. The DNA concentration and purity were evaluated on a NanoDrop 1000 (Thermo Scientific; Wilmington, DE).

\section{B. Test methods}

All testing was performed at ambient temperature $\left(25-30^{\circ} \mathrm{C}\right)$ unless otherwise noted.

1. SmartCycler

The Cepheid SmartCycler System is a rapid thermal cycling PCR instrument platform with real-time 4channel detection and solid-state optics housed in 16 (expandable to 96) individual modules. The coupling of patented SmartTube and SmartCap technology with forced air and ceramic heater plates having high thermal conductivity yields average PCR time-to-results of 20-40 minutes per sample run. 


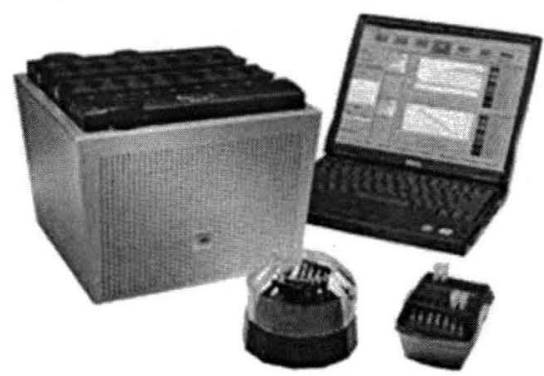

Figure 3. Cepheid's Smartcycler ${ }^{\circledR}$ instrument. A 16-well real-time PCR instrument with an external computer interface and accessories. Image from Cepheid (www.cepheid.com)

\section{RAZOR EX}

RAZOR testing was performed using $100 \mu \mathrm{L}$ of whole cells or DNA preparations according to the test plan. The samples were run in triplicate on each pouch, so a syringe was loaded to a volume of $400 \mu \mathrm{L}$, which was then injected into the pouch through a cannula (Fig. 4). The pouches are vacuum sealed and when the seal is broken, the exact amount required for each sample is loaded into each well. The pouch was identified in the system using a barcode scanner, then loaded into the slot to begin a sample run for 25 minutes. At the start of each run, the pouch is heat sealed to prevent leaks. At the end of each run, the results are shown on the display screen of the instrument or can be exported with additional details.

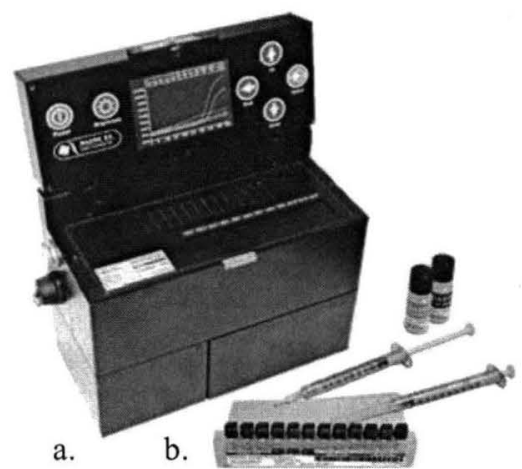

Figure 4. RAZOR EX hardware. a. Portable machine that performs reaction and analysis. b. Sample pouch and associated sample collection and injection syringes. Image from BioFire Diagnostics website: $\quad$ http://www.biofiredx.com/ RAZOREX/index.html.

3. iCubate

The iCubate testing was performed using $40 \mu \mathrm{L}$ of whole cells or $10 \mu \mathrm{L}$ of DNA loaded into the first well of the cassette (Fig. 5a). The cassette was identified in the computer system using a barcode scanner, then loaded into the processor to begin a sample run for 4 (DNA) to 6 hours (whole cells including extraction) (Fig. 5b). After the run, the cassettes were transferred to the reader for analysis (about 5 minutes) and the results generated by the reader were analyzed (Fig. 5c). Each cassette can detect up to 30 different targets in addition to positive and negative controls.

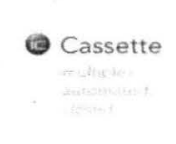

a.

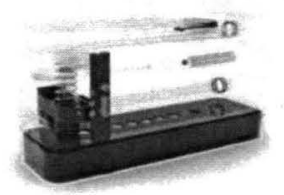

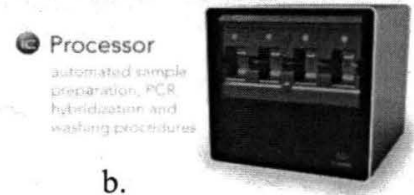

b.

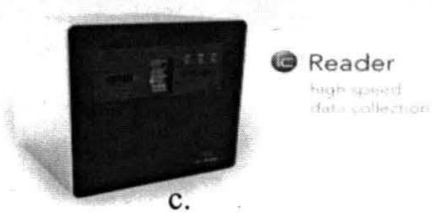

Figure 5. iCubate hardware. a. Cassette that is pre-loaded with required PCR reagents. b. Processor. c. Reader. Images from iCubate website: www.icubate.com reproduced with permission.

\section{Analysis and Reporting}

Each platform had a unique standard software analysis package. Each group analyzed the data using the platform-associated software and reported the data to the multi-center group. Testing determined that the LLOD for 
S. enterica was $1 \times 10^{3}$ (SmartCycler) to $1 \times 10^{4}$ (RAZOR and iCubate) shown in Table 1 below. Results from the testing using a negative control organism (Pseudomonas) showed that the concentration of $S$. enterica needed to detect it in a mixed bacterial sample was one log greater than the concentration needed to detect it in an unmixed sample. The ISS water did not contain detectable levels of $S$. enterica in any of the platforms evaluated.

Table 1: Results of the proof-of-concept testing demonstrating the ability of each platform tested to detect Salmonella enterica at a range of $1 \times 10^{3}$ to $1 \times 10^{4}$ using between 50 and 400 cells per reaction.

\begin{tabular}{|l|l|l|l|l|}
\hline \multicolumn{1}{|c|}{ Platform } & Reaction Volume & \multicolumn{1}{|c|}{$\begin{array}{c}\text { LLOD } \\
\text { Salmonella } \\
\text { enterica }\end{array}$} & $\begin{array}{c}\text { LLOD of } \\
\text { Salmonella enterica } \\
\text { with Pseudomonas } \\
(\mathbf{1 : 1} \text { dilution })\end{array}$ & $\begin{array}{l}\text { Number of cells } \\
\text { needed per } \\
\text { reaction }\end{array}$ \\
\hline SmartCycler & $\begin{array}{l}1 \mu \mathrm{L} \text { of extracted } \\
\text { DNA }\end{array}$ & $1 \times 10^{3}$ & $1 \times 10^{4}$ & 94 \\
\hline RAZOR & $\begin{array}{l}100 \mu \mathrm{L} \text { of whole } \\
\text { cells }\end{array}$ & $1 \times 10^{4}$ & $1 \times 10^{5}$ & 50 \\
\hline iCubate 2.0 & $\begin{array}{l}40 \mu \mathrm{L} \text { of whole } \\
\text { cells or } 10 \mu \mathrm{L} \text { III. } \\
\text { DNA }\end{array}$ & $\begin{array}{l}1 \times 10^{4} \\
\text { Discussion and }\end{array}$ & $\begin{array}{l}1 \times 10^{5}\left(1 \times 10^{4} \text { was }\right. \\
\text { not tested) } \\
\text { Conclusions }\end{array}$ & 400 \\
\hline
\end{tabular}

The three hardware units tested had the capability to detect $\leq 400$ cells of $S$. enterica per sample. Both the RAZOR and iCubate technologies used sample-to-answer methodologies in contained systems and were recommended for further consideration. Although the SmartCycler was able to detect $94 \mathrm{cells} / \mathrm{sample}$ during the proof-of-concept testing, it was not considered for further evaluation for flight feasibility for several reasons:

1. Labor intensive - requires additional extraction procedures, which would increase crew time and amount of equipment needed.

2. Sample containment - the additional sample handling could lead to sample contamination as well as amplicon contamination of the environment, compromising all future PCR reactions.

As a result of the survey and intial testing, the following requirements were developed for future technologies and will be used during the competitive request for proposal process to identify technologies that have the ability to perform the science requirements needed for operational use during space flight:

a. Shall be able to simultaneously analyze (quantification or semi-quantification AND identification) at least 20 targeted microbial populations (viruses, bacteria, and fungi) in water samples using culture-independent molecular methodologies.

b. Shall be automated, requiring minimal crew time to prepare and analyze samples. The equipment shall be capable of providing molecular-based sample-to-answer analysis and data output, without the need for the crew to assist in the process.

c. Shall have a detection limit $\leq 400$ cells/sample using $\leq 100 \mu \mathrm{l}$ of sample volume per reaction.

d. If any potentially hazardous liquids are needed, the equipment shall have two levels of containment to avoid contamination of the Microbial Monitoring System (MMS) and/or cross-contamination between reagents or DNA products.

e. Shall have the ability to make customized target detection assays.

f. Shall have portability, which would allow the MMS to be set up quickly and operated without complicated setup and assembly.

g. Shall have the flexibility for the MMS to be used outside of a standard laboratory by non-microbiologists.

$\mathrm{h}$. Shall be capable of utilizing a molecular identification system designed to support microorganism identification and a degree of quantification.

i. Instrument platform shall consist of a portable thermal cycler with built-in, on-board signal detection, analysis, and identification software.

j. Instrument shall have the capability for connection via USB or other protocol.

k. Accurate qualitative results for microorganism detection shall be available from the instrument in less than six (6) hours.

1. To minimize requirements for crew time and hazards associated with sample processing on orbit, the selected instrument shall have pre-made, pre-mixed reagent mixtures containing all of the reagents and reaction components necessary. 
m. The equipment shall provide analysis of multiplex or multiple targets in one batch of sample containing at least four (4) targets.

n. Reagents shall not require refrigeration during storage. Sample modules shall be able to be stored at room temperature for a minimum of six (6) months.

o. The equipment shall provide data from processed samples. These data shall be readily available to store electronically for trend analysis.

Future work will include submitting a request for quotations that identify any additional current technologies that meet the needs for space flight application, and evaluation of these technologies for potential synergy with other efforts being performed by the WetLab2 and MiDASS groups. 


\section{Appendix}

Market Survey Performed in Spring 2012 Identifying the Current Commercial-Off-the-Shelf Quantitative Polymerase Chain Reaction (PCR) Candidates

(Data are from product Web sites and/or published brochures.)

\begin{tabular}{|c|c|c|c|c|}
\hline & $\begin{array}{c}\text { 3.1.1 } \\
\text { Idaho Technology, Inc. } \\
\text { RAZOR EX }\end{array}$ & $\begin{array}{c}3.1 .2 \\
\text { Cepheid } \\
\text { SmartCycler }\end{array}$ & $\begin{array}{c}3.1 .3 \\
\text { iCubate } \\
\text { iCubate } 2.0\end{array}$ & $\begin{array}{c}3.1 .4 \\
\text { Idaho Technology, Inc. } \\
\text { Film Array* }\end{array}$ \\
\hline 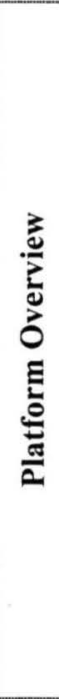 & $\begin{array}{l}\text { Made for field use, the RAZOR } \\
\text { EX is compact, lightweight, and } \\
\text { easy to use. Created for first } \\
\text { responders and front line } \\
\text { military troops, it is easily } \\
\text { operated while working in } \\
\text { protective equipment under } \\
\text { extreme conditions. It can run up } \\
\text { to } 12 \text { reactions per sample } \\
\text { pouch. Pouches are pre-loaded } \\
\text { with freeze-dried PCR reagents. } \\
\text { No refrigeration or freezing is } \\
\text { necessary. Results are available } \\
\text { in less than } 30 \text { min. }\end{array}$ & $\begin{array}{l}\text { Cepheid's SmartCycler }{ }^{\circledR} \text { instrument is a random- } \\
\text { access, modular real-time PCR instrument. Test } \\
\text { up to } 16 \text { different protocols at a time. At the heart } \\
\text { of the SmartCycler System is the I -CORE® } \\
\text { module-a reliable, solid-state optical system } \\
\text { with no moving parts. Each of the standard } 16 \text { I- } \\
\text { CORE® modules (expandable to 96) requires no } \\
\text { warm-up time, no routine maintenance, and no } \\
\text { normalization dye. The SmartCycler System is } \\
\text { highly robust and compact, with no moving } \\
\text { components-ideally suited for mobile use in } \\
\text { field-testing applications. Sealed, pressurized } \\
\text { polypropylene SmartTube system designed to } \\
\text { minimize the risk of amplicon contamination, } \\
\text { maximize heat transfer, and optimize optical } \\
\text { sensitivity. Preinstalled software enables each of } \\
\text { the reaction sites to be operated independently. } \\
\text { Monitoring of thermal and optical data is in real } \\
\text { time, and graphs of temperature, growth and melt } \\
\text { curves are displayed during data collection. }\end{array}$ & $\begin{array}{l}\text { Includes one Reader, one } \\
\text { Processor, and a computer with } \\
\text { preinstalled software. Internal } \\
\text { and external barcodes scanners } \\
\text { located throughout the system } \\
\text { will ensure error free } \\
\text { processing and tracking of } \\
\text { samples. iCubate disposable } \\
\text { cassettes come pre-loaded with } \\
\text { specified reagents. Computer } \\
\text { controlled robotics allow for } \\
\text { automated sample prep, PCR, } \\
\text { hybridization and washing } \\
\text { procedures to be performed. } \\
\text { Each Processor can run from } \\
\text { one to four cassettes, each } \\
\text { containing } 12 \text { samples. }\end{array}$ & $\begin{array}{l}\text { User-friendly multiplex PCR all- } \\
\text { in-one system integrates sample } \\
\text { preparation, amplification, } \\
\text { detection and analysis into one } \\
\text { instrument that processes sample to } \\
\text { results in less than one hour. } \\
\text { The FilmArray reagent pouch } \\
\text { stores all the necessary reagents } \\
\text { from sample preparation, reverse } \\
\text { transcription-PCR, PCR, and } \\
\text { detection in a freeze-dried format. } \\
\text { Prior to a run, the user injects } \\
\text { hydration solution and unprocessed } \\
\text { sample into the pouch. The } \\
\text { FilmArray extracts and purifies all } \\
\text { nucleic acids from the unprocessed } \\
\text { sample. It then performs a nested } \\
\text { multiplex PCR. }\end{array}$ \\
\hline
\end{tabular}




\begin{tabular}{|c|c|c|c|c|}
\hline 总 & $\begin{array}{l}\text { - RAZOR EX Instrument, } 11 \mathrm{lb} \text {, } \\
25.4 \times 11.4 \times 19 \text { in. (including } \\
\text { battery) } \\
\text { - Battery recharger } \\
\text { - Battery pack } \\
\text { - } 24 \mathrm{~V}, 4 \mathrm{~A} \text { power supply } \\
\text { - USB data cable } \\
\text { - Air filter assembly } \\
\text { - Tools: } 5.5^{\prime \prime} \text { Needle-nose } \\
\text { pliers, lens cleaning solution, \& } \\
\text { tissue } \\
\text { - Assay Target Pouch } \\
\text { - Prep Kit: Buffers, syringes, } \\
\text { samples bottles, swabs, pipettes }\end{array}$ & $\begin{array}{l}\text { - Processing Block, } 22 \mathrm{lb}, 12 \times 12 \times 10 \text { in. } \\
\text { - I-Core Module } \\
\text { - Smart Tubes } \\
\text { - Mini centrifuge with SmartTube adapter } \\
\text { - SmartTube racks } \\
\text { - Cooling block } \\
\text { - Preinstalled software }\end{array}$ & $\begin{array}{ll}- & \text { Reader, } 75 \mathrm{lb}, \\
14 \times 15 \times 14 \mathrm{in} . \\
\text { - } & \text { Processor, } 102 \mathrm{lb}, \\
17 \times 17 \times 17 \mathrm{in} . \\
\text { - } \\
\text { Computer with } \\
\text { preinstalled software } \\
\text { iCubate disposable } \\
\text { cassettes, preloaded } \\
\text { with specified } \\
\text { reagents. }\end{array}$ & $\begin{array}{ll}- & 20 \mathrm{lb}, 10 \times 15.5 \times 6.5 \text { in. } \\
- & \text { Windows-based } \\
\text { instrument control and } \\
\text { data analysis software } \\
\text { - } \quad \begin{array}{l}\text { Barcode reader for data } \\
\text { input } \\
\text { - }\end{array} \\
\text { Automated qualitative } \\
\text { analysis and reporting } \\
\text { - Separate advanced } \\
\text { analysis software }\end{array}$ \\
\hline 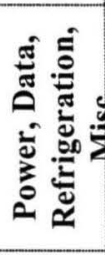 & $\begin{array}{l}\text { - Instrument is battery powered, } \\
\text { but is } 110 / 220 \text { V compatible. } \\
\text { - USB data cable (or wireless) } \\
\text { connectivity to Windows XP. } \\
\text { - No additional thermal } \\
\text { requirements for instrument or } \\
\text { sample pouches. }\end{array}$ & $\begin{array}{l}\text { - } 100-240 \mathrm{~V} \mathrm{ac}, 50-60 \mathrm{~Hz}, 350 \mathrm{~W} \\
\text { - Many of the primers \& probes (reagents) must } \\
\text { be refrigerated. } \\
\text { - SmartTubes are } 1 \times \text { use only (disposable). } \\
\text { - The optical system has no moving parts to get } \\
\text { out of alignment or bulbs to be damaged during } \\
\text { transport. }\end{array}$ & $\begin{array}{l}\text { - All } 3 \text { components need } 110 \text { - } \\
240 \mathrm{~V} \text { ac, } 5 \mathrm{~A} \text {. } \\
\text { - Reagent trays must be } \\
\text { refrigerated. } \\
\text {-? Connectivity to computer }\end{array}$ & $\begin{array}{l}-90-264 \mathrm{~V} \mathrm{ac}, 10 \mathrm{~A} \\
\text { - Storage at }-30^{\circ} \mathrm{C} \text { to } 65^{\circ} \mathrm{C} \\
\text { - Operating at } 15^{\circ} \mathrm{C} \text { to } 30^{\circ} \mathrm{C}, 20 \% \\
\text { to } 80 \% \text { humidity }\end{array}$ \\
\hline & $\begin{array}{l}\text { RAZOR E EX Instrument } \\
25.4 \times 11.4 \times 19 \text { in., } 11 \mathrm{lb}\end{array}$ & $\begin{array}{c}0.0000 \\
\text { Processing Block } \\
12 \times 12 \times 10 \text { in., } 22 \mathrm{lb}\end{array}$ & 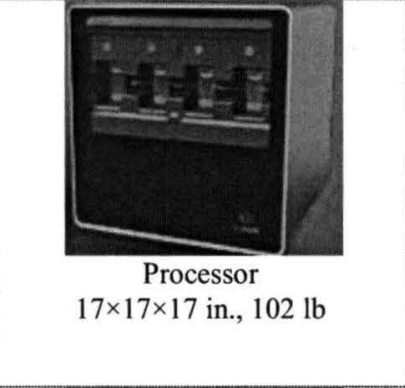 & FilmArray Instrument \\
\hline 党 & Sample Pouch & Reaction Tube & $\begin{array}{c}\text { Reader } \\
14 \times 15 \times 14 \text { in., } 75 \mathrm{lb}\end{array}$ & Pouch Loading Station \\
\hline
\end{tabular}




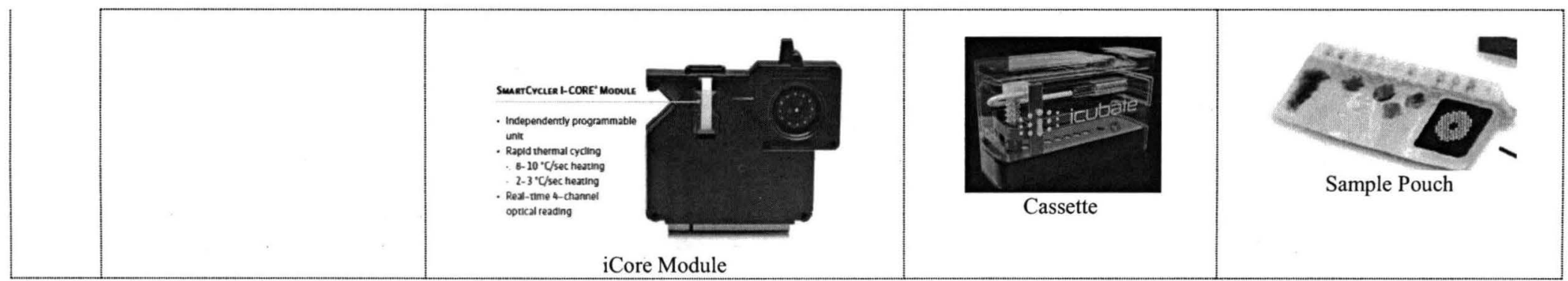

* Proof-of-concept testing was not performed on the FilmArray technology because it was not commercially available at the time testing was initiated. 


\section{References}

${ }^{1}$ Pierson, D. L., "Microbial Contamination of Spacecraft," Gravitational and Space Biology Bulletin, Vol. 14, No. 2, 2001, pp. 16.

${ }^{2}$ Cioletti, L. A., Mishra, S. K., Pierson, D. L., and Koenig, D. W., "Microbiology Standards for the International Space Station," 25th International Conference on Environmental Systems, Society of Automotive Engineers, San Diego, CA, 1995. SAE Technical Papers, 951682.

${ }^{3}$ Pierson, D., Botkin, D. J., Bruce, R. J., Castro, V. A., Smith, M. J., Oubre, C. M., Ott, C. M., "Microbial Monitoring of the International Space Station," in Environmental Monitoring: A Comprehensive Handbook, edited by J. Moldenhauer, DHI Publishing: River Grove, IL., 2012, pp. 1-27.

${ }^{4}$ National Aeronautics and Space Administration (NASA), NASA Microbiology Workshop, NASA/CP-2012-217460, 2011.

${ }^{5}$ Han, J., "Multiplex PCR: Methods, Utility, and Platforms," Advanced Technologies in Diagnostic Microbiology, edited by Y. Tang and C. W. Stratton, Springer Publishing: New York, 2013, pp. 627-646. 